\title{
Theropods on top
}

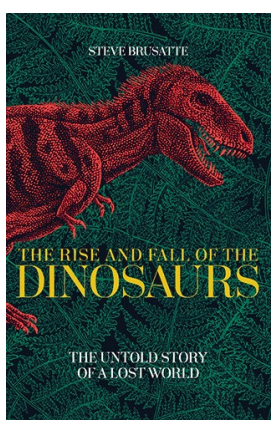

methodologies and findings concisely but entirely comprehensibly.

Throughout, the reader is introduced to a cast of characters who have influenced Brusatte's career, from undergraduate mentors to current collaborators. Some of these accounts smack somewhat of heroworship, and others are a touch patronizing: the repeated referral to a number of my colleagues who hold senior university positions (and are in their late thirties, at best) as 'young guns' irked me somewhat, although there is no doubt that these characterizations enrich the story and the science. I particularly enjoyed the account of the life of Baron Franz Nopcsa von Felső-Szilvás, an aristocrat, prolific fossil collector and Austro-Hungarian spy from the early part of the twentieth century. The flamboyant, fascinating and ultimately tragic life of a man whose contributions are still regularly referenced in the palaeontological literature, and whose finds can be viewed today in London's Natural History Museum, is told with both sensitivity and humour.

Brusatte's writing is at its best when he is conjuring up imagery to describe a day in the life of a dinosaur, or the Late Triassic Pangaean world. His description of the events that would have occurred on the last day of the Cretaceous - when a meteorite $10 \mathrm{~km}$ in diameter hit what is now Mexico and caused one of the largest mass extinctions of the past 541 million years - from the perspective of a T. rex is vivid and delightful. A flash of light so bright that it would have blinded animals in North America; the Earth's surface turning into a 'trampoline' as the magnitude of 11 earthquakes rocked it. Brusatte goes on to provide evidence for these events, detailing how geologists and physicists worked out what happened during the cataclysm. This elevates the narrative from a Jurassic Park style work of fiction to a detailed, rigorous scientific account. I thoroughly enjoyed these parts of the book and I found it difficult to put down.

I got somewhat out-T. rex-ed, though, in the middle section. Brusatte first details the evolutionary history of the tyrannosaurs, the broader group to which T. rex belongs, describing the discovery and subsequent study of several members of the group, to which Brusatte himself has contributed. After this, an entire chapter is dedicated to all of the research that has been done on T. rex, from feeding, locomotion, visual acuity and sense of smell, to the function of its seemingly pointless tiny arms. While Brusatte is very good at choosing appropriate analogies to explain complex biomechanical and engineering techniques to a non-specialist audience, all of this information about a single animal, even if it is an icon of a lost world, was too much for me, and my interest in this section waned. But this is very much a personal account, and the way the book is written, from the chatty style full of Americanisms to the descriptions of Brusatte's own work, mean that at least some focus on T. rex was inevitable.

Overall I think this book will be a huge hit among dinosaur fans everywhere. Many a student CV has crossed my desk crowned with a sentence about how much they love the 'meat-eating' theropods, and this book will find a dedicated and enthusiastic audience among theropod geeks everywhere. But Brusatte's broad general knowledge, the diversity of the work that he himself has carried out and his ability to vividly reimagine the past elevate it from dinogeekdom, meaning that it should also be taken seriously by those with a broad general interest in the world of the past, and who want to find out more about the scientific methods that are used to investigate it.

Reviewed by Susannah Maidment Susannah Maidment is a Researcher in Mesozoic Reptiles at the Natural History Museum, London, UK.

e-mail:susannah.maidment@nhm.ac.uk

Published online: 28 May 2018 https://doi.org/10.1038/s41559-018-0571-x 